in vivo $35: 333-339(2021)$

doi:10.21873/invivo.12264

\title{
Expression of Syndecan-1 in Chronic Liver Diseases: Correlation With Hepatic Fibrosis
}

\author{
ANTONIA CHARCHANTI ${ }^{1}$, PANAGIOTIS KANAVAROS ${ }^{1}$, EFTHYMIOS KONIARIS ${ }^{2}$, \\ AGAPI KATAKI $^{3}$, GEORGIOS GLANTZOUNIS ${ }^{4}$, NIKI J. AGNANTIS ${ }^{5}$ and ANNA C. GOUSSIA ${ }^{5}$ \\ ${ }^{1}$ Department of Anatomy-Histology-Embryology, Faculty of Medicine, \\ School of Health Sciences, University of Ioannina, Ioannina, Greece; \\ ${ }^{2}$ Department of Pathology-Anatomy, Hippocration Hospital of Athens, Athens \\ Medical School, National and Kapodistrian University of Athens, Athens, Greece; \\ ${ }^{3}$ Laboratory of Surgical Research, First Department of Propaedeutic Surgery, Hippocration \\ Hospital, Athens Medical School, National and Kapodistrian University of Athens, Athens, Greece; \\ ${ }^{4}$ Department of Surgery, Faculty of Medicine, School of Health Sciences, University of Ioannina, Ioannina, Greece; \\ ${ }^{5}$ Department of Pathology, Faculty of Medicine, School of Health Sciences, \\ University of Ioannina, Ioannina, Greece
}

\begin{abstract}
Background/Aim: The mechanisms underlying the contribution of the heparan sulfate proteoglycan syndecan-1 to liver tissue injury and to crucial biological processes, such as fibrogenesis, remain to be elucidated. Therefore, we investigated the immunohistochemical expression of syndecan-1 in chronic liver diseases (CLDs) and its probable role in hepatic fibrosis. Materials and Methods: Immunohistochemistry was performed on formalin-fixed, paraffin-embedded tissue sections of biopsy material obtained from 128 patients diagnosed with CLDs. The correlation between syndecan-1 expression and the stage of fibrosis was investigated. Results: According to the severity of fibrosis, cases were categorized into three groups: early fibrosis; intermediate fibrosis; advanced fibrosis. Syndecan-1 expression was significantly enhanced in advanced fibrosis compared to early $(p<0.012)$ and intermediate $(p<0.003)$ fibrosis. Conclusion: In CLDs, syndecan-1 immunohisto-chemical overexpression was found to be positively correlated with the severity of fibrosis, suggesting its probable role in hepatic fibrogenesis.
\end{abstract}

This article is freely accessible online.

Correspondence to: Antonia Charchanti, Department of AnatomyHistology-Embryology, Faculty of Medicine, School of Health Sciences, University of Ioannina, 45110, Ioannina, Greece. E-mail: antoniacharchanti@gmail.com

Key Words: Heparan sulfate proteoglycans, immunohistochemistry, liver fibrosis, syndecan-1.
Liver fibrosis constitutes one of the most important responses of the liver to persistent tissue damage, due to a variety of pathological insults, including hepatitis virus infection, alcohol consumption, toxins, and autoimmune or metabolic disorders (1-3). It is a dynamic wound-healing process that reflects an imbalance between the production and remodeling of the extracellular matrix (ECM), which leads to altered and excessive accumulation of ECM components and therefore to the disruption of the normal tissue architecture (1-3). The progressive accumulation of ECM observed during fibrogenesis is due to the production of large amounts of proteins such as proteoglycans, collagens, fibronectin, and is driven by liver fibrogenic cells, especially myofibroblasts, which originate mainly from activated hepatic stellate cells (HSCs) (2-4). Among others, inflammatory cells such as macrophages, and cytokines as well as signaling pathways [e.g. transforming growth factor- $\beta 1$ (TGF $\beta 1$ )/SMAD family member 3 (SMAD3) pathway] seem to participate in the fibrogenetic process after liver injury $(2,3)$.

ECM remodelling is important for the preservation of liver tissue homeostasis and depends largely on the balance between matrix metalloproteinases (MMPs) and their inhibitors (TIMPs). Studies have shown that increased amounts of TIMPs can promote liver fibrosis by their antiapoptotic function on HSCs $(5,6)$. Moreover, a growing body of evidence also suggests that the heparan sulfate proteoglycans (HSPGs), syndecans, can affect ECM assembly and turnover (7). Syndecans are a family of four proteoglycans in mammals, syndecans 1 to 4 . Structurally, they consist of three domains: an extracellular domain (ectodomain), a transmembrane domain, and a cytoplasmic 
domain (8-11). The extracellular domain is the most wellcharacterized region that carries glycosaminoglycan (GAG) side chains, which enable important interactions with growth factors, cytokines, chemokines, ECM molecules and enzymes $(7,11,12)$. As a result of ligand interactions, syndecans stimulate a variety of biological signaling events related to integrin-mediated cell adhesion, inflammation, wound healing and fibrosis $(9,12-14)$.

Experimental models of tissue injury have suggested the important role of syndecan-1 in inflammatory, reparative and fibrotic processes $(12,15,16)$. In injured areas, the activation of proteases may lead to cleavage off of the ectodomain, a process which is known as shedding. The shed ectodomain has been found to induce cell signals through presentation of ligands with cognate receptors (15). In inflammatory processes, both shed and exogeneous syndecan-1 ectodomains may induce neutrophil chemotaxis and the shed form may regulate chemokine activities $(15,16)$. Increased syndecan- 1 shedding has been correlated with wound repair, and in fibrotic areas, both forms of ectodomains have been found to be accumulated within the ECM (12).

Studies in injured lung and heart tissue suggested the implication of syndecan-1 in the pathogenesis of organ fibrosis (13, 17-20). In murine experimental models of lung fibrosis, syndecan- 1 overexpression has been observed in the alveolar epithelium of fibrotic regions from bleomycininjured lungs (13). Interestingly, wild-type mice had higher lung collagen content and a profibrotic gene-expression profile compared to syndecan-1 deficient mice. Similar findings of syndecan- 1 overexpression have been shown in lung samples from patients with idiopathic pulmonary fibrosis (13). In heart injury, experiments using syndecan-1 knock-out mice subjected to myocardial infarction have shown adverse infarct healing, collagen disorganization and fragmentation due to the increased activity of MMPs, as well as to the alterations of recruitment of inflammatory cells (21). In contrast, syndecan-1 overexpression improved the formation of collagen matrix and protected against rupture post-myocardial infarction (21).

In liver tissue, syndecan- 1 is expressed in abundance on the surface of hepatocytes. It mediates the clearance of triglyceride-rich lipoproteins and it is up-regulated after infection by hepatitis virus (22-24). These observations suggest that syndecan-1 may play a role in response to agents that are metabolized by the liver and to agents that cause liver disease. In an experimental mouse model with liver injury induced by a hepatotoxic metabolite produced after acetaminophen overdose, it was found that syndecan-1 may limit the progression of tissue injury and may promote tissue repair, probably by controlling the balance between protein kinase $\mathrm{B}$ (AKT) activation of pro-survival signaling and glycogen synthase kinase- $3 \beta$-mediated apoptosis $(25,26)$. In earlier publications, increased syndecan-1 tissue expression and serum levels of the shed ectodomain have been
Table I. Fibrosis group and pathogenesis.

\begin{tabular}{lrrrr}
\hline & \multicolumn{4}{c}{ Fibrosis, n } \\
\cline { 2 - 5 } & Early & Intermediate & Advanced & Total \\
\hline Pathogenesis & 37 & 5 & 11 & 53 \\
Steatohepatitis & 19 & 13 & 3 & 35 \\
Hepatitis B & 6 & 3 & 3 & 12 \\
Hepatitis C & 4 & 1 & 2 & 7 \\
Drug-induced hepatitis & 10 & 6 & 5 & 21 \\
Autoimmune hepatitis & 76 & 28 & 24 & 128 \\
\hline Total & & & & \\
\hline
\end{tabular}

demonstrated in human liver diseases, such as nonalcoholic fatty liver disease, cirrhosis and even hepatocellular carcinoma $(26,27)$. In addition, the serum concentration of the shed syndecan- 1 has been associated with the severity of fibrosis, underlying its potential value for disease monitoring $(27,28)$. However, it was shown recently that syndecan-1 inhibits the early stages of liver fibrogenesis, probably by eliminating TGF $\beta 1$ or by hindering its activation by interfering with its major activator thrombospondin-1 (29). Interestingly, the protective effect of syndecan-1 was found to change over time and a significant decrease in its expression during the later stages of fibrosis was found.

Despite the accumulating data on the biological function of syndecan-1, the significance of its altered expression remains to be determined. Herein, we investigated the immunohistochemical expression of syndecan-1 in CLDs and its probable role in hepatic fibrosis.

\section{Materials and Methods}

Tissue material. Tissue material consisted of 128 cases of CLDs that had been diagnosed on the basis of routine stains during liver biopsy interpretation (Table I). The protocol was approved by the Ethics Committee of the University Hospital of Ioannina (May 23, 2019) which allowed the use of biological material for research purposes.

The median age of the study population at the time of diagnosis was 50 years (range $=16-88$ years). Males and females accounted for $54.7 \%(n=70)$ and $45.3 \%(n=58)$, respectively. Paraffin blocks of tissue biopsies were retrieved from the archives of the Department of Pathology, Faculty of Medicine, School of Health and Sciences, University of Ioannina and histological sections 3 - to $4-\mu \mathrm{m}$-thick were prepared.

During the diagnostic procedure, the stage of fibrosis was assessed in all cases using traditional staging systems $(30,31)$. In order to provide more meaningful information, we categorized our cases into three groups according to the severity of fibrosis as follows: Early fibrosis: No fibrosis or perisinusoidal or portal/periportal fibrosis; Intermediate fibrosis: Perisinusoidal and portal/periportal or bridging fibrosis. Advanced fibrosis; Fibrous septa with focal or diffuse nodularity or established cirrhosis (Table I). 

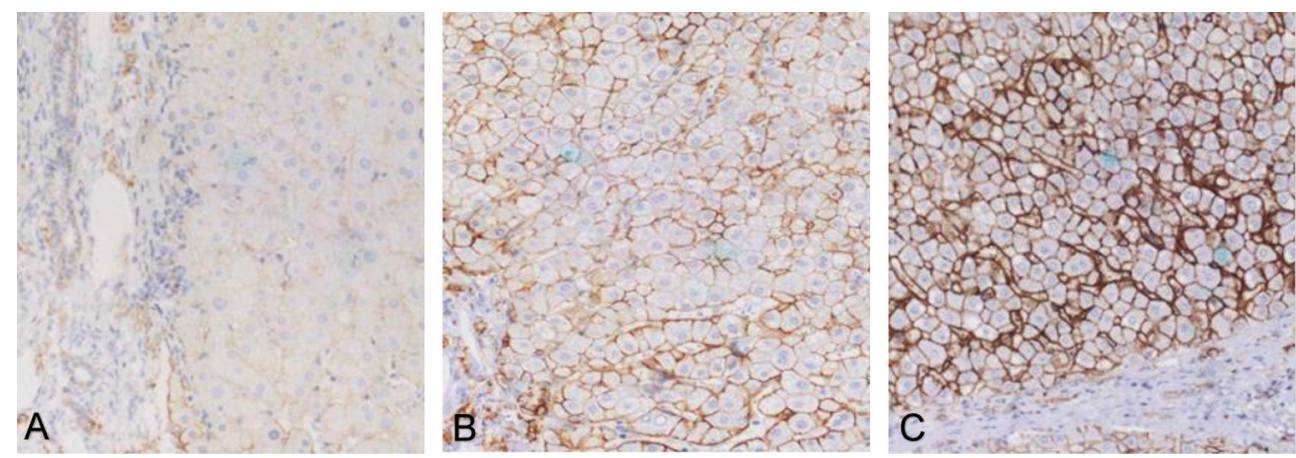

Figure 1. Syndecan-1 immunohistochemistry in early (A), intermediate (B) and advanced (C) liver fibrosis. Magnification: 200x.

Five cases of liver biopsies without evidence of pathology served as normal control liver samples.

Immunohistochemistry. Immunohistochemical staining for syndecan-1 was performed on formalin-fixed, paraffin-embedded tissue sections with the standard avidin-biotin-immunoperoxidase method (Elite ABC Kit, Vectastain; Vector, Burlingame, CA, USA) according to the instructions of the supplier of the mouse monoclonal antibody against human syndecan-1 (B-B4; Serotex, Oxford, UK) was used. Negative controls (omission of the primary antibody) were used in all experiments.

For assessment of immunohistochemical expression of syndecan1, a semiquantitative immunohistochemical score (H-score), was used. The score was calculated by multiplying the percentage of positively stained hepatocytes by the staining intensity using the following formula: $[1 \times(\%$ weakly positive area $)+2 \times(\%$ moderately positive area $)+3 \times(\%$ strongly positive area $)]$. Immunohistochemical evaluation was performed by two histopathologists.

Statistical analysis. For statistical analyses, IBM SPSS version 25 (IBM, Armonk, NY, USA) software package was used and significance levels were tested by Student's $t$-test for normally distributed data or Mann-Whitney $U$-test for non-normally distributed data, or using the chi-square for categorical variables. The statistical difference between more than two groups was evaluated by Kruskal-Wallis one-way ANOVA. The results were considered as statistically significant when $p<0.05$.

\section{Results}

Immunohistochemical expression of syndecan-1 in normal liver tissue. All cases with normal liver tissue showed a positive reaction to syndecan-1 antibody, with pale brown staining mostly along the sinusoidal surface of hepatocytes, as a primary sinusoidal pattern of immunostaining. The staining intensity was weak to moderate. Moreover, the lateral surface of hepatocytes showed focal membranous immunostaining or no immunostaining.

Immunohistochemical expression of syndecan-1 in CLDs. In the group of cases with early liver fibrosis, syndecan-1 exhibited a sinusoidal immunostaining pattern along with
Table II. Syndecan-1 expression in patients with different stages of liver fibrosis.

\begin{tabular}{lccl}
\hline Fibrosis group & $\mathrm{N}$ & $\begin{array}{c}\text { IRS H-score, } \\
\text { mean } \pm \text { SD }\end{array}$ & $p$-Value* \\
\hline Early & 76 & $206.66 \pm 68.066$ & \\
Intermediate & 28 & $189.46 \pm 61.544$ & $\mathbf{0 . 1 9 2}$ vs. Early \\
Advanced & 24 & $243.75 \pm 51.526$ & $\mathbf{0 . 0 1 2}$ vs. Early \\
& & & $\mathbf{0 . 0 0 3}$ vs. Intermediate \\
\hline
\end{tabular}

Total

128

*Mann-Whitney $U$-test. Statistically significant $p$-values are shown in bold.

extension of the immunostaining on the lateral surfaces of hepatocytes. The immunostaining intensity was mild to moderate (Figure 1A).

In groups with intermediate and advanced fibrosis, syndecan-1 staining gradually extended to almost the entire cell membrane, creating a honeycomb-like immunostaining pattern. The staining intensity was moderate to strong (Figure 1B and C).

Statistical analysis showed that syndecan-1 expression was significantly enhanced in the advanced fibrosis compared to the early and intermediate fibrosis $(p<0.012$ and $p<0.003$, respectively) (Table II).

No correlation of syndecan-1 expression with patient age and sex was observed. In addition, syndecan-1 expression did not show any correlation with the etiology (e.g. viral hepatitis, alcohol intake) of liver disease.

\section{Discussion}

Fibrosis is a consequence of CLDs due to various etiologies. Recent clinical evidence has changed the initial belief that advanced fibrosis, cirrhosis, is always irreversible and even in humans, successful treatment of the underlying disease may lead to regression of fibrosis $(2,32-34)$. Understanding 
the mechanisms of fibrogenesis may improve diagnostic and therapeutic approaches. After intensive experimental research, it became evident that liver fibrogenesis is a dynamic wound-healing process that requires the interactions of several cell types, the alterations of many structural molecules and the dysregulation of several intracellular signaling pathways $(2,3)$. Multiple evidence implicates syndecan-1 in tissue injury as well as in inflammatory, regenerative, fibrogenic and neoplastic processes $(12,15,16$, $26,35)$. Since syndecan- 1 has be found to be required for wound healing and liver fibrosis is closed related to wound healing and formation of scar, it is apparent that syndecan-1 expression in fibrotic liver may have clinical significance.

In the present study and in agreement with previous studies (36-38) we found syndecan-1 immunostaining in normal liver tissue mostly along the sinusoidal surface of hepatocytes in contrast to the lateral surface, where no or only faint staining was observed. The distribution pattern of syndecan-1 staining reflects its specific localization in liver tissue and may explain some of its biological functions. On the surface of hepatocytes, syndecan- 1 is localized to the Disse space $(22,36,39)$. This location is a unique environment, where there is a high concentration of lipoproteins and ligands (22). This evidence may explain why syndecan-1 is considered a major receptor involved in the clearance of triglyceride-rich lipoproteins. In addition, the fact that the GAG side chains of syndecan-1 ectodomain in liver contain more binding sites for lipoproteins may explain why syndecan-1 mediates clearance in liver but not in other tissues (22). Hepatocyte polarization and canalicular network formation are essential for many liver functions and require a coordinated expression of several key elements, such as ECM, adherens and tight junctions, cytoskeletal microfilaments and microtubular systems 40). Syndecan-1 links cells to the interstitial matrix and connects the matrix with the intracellular cytoskeleton $(15,36)$. Thus, syndecan-1 is required for the maintenance of epithelial and matrix organization. Taking into consideration its specific localization, it seems that syndecan-1 is correlated with hepatocyte polarization. The process of hepatocyte polarization seems to be important in liver response to agents that, if abnormal, may cause liver disease. Hepatitis B virus entry into hepatocytes is dependent on cell polarization and suggests that the possible viral cell receptor may be located in the basolateral membranes (40). This may explain the up-regulation of syndecan-1 after hepatitis virus infection. A major role of syndecans is their action as co-receptors, regulating cell signaling and cell behavior (41). Given the specific immunolocalization of syndecan-1, one can postulate that its co-operation with other receptors may be important for the regulation of normal liver function and tissue homeostasis (36).

In cases of liver diseases, compared to normal liver, an altered immunolocalization of syndecan-1 was observed, reflected either by sinusoidal hepatocyte surface staining with extension to the lateral surface or by entire cell membrane staining. Interestingly, these changes in localization were associated with changes in staining intensity along with the fibrosis status. Specifically, in intermediate and advanced stages of fibrosis, the staining intensity was significantly more robust than in early stages and the staining was gradually extended to almost the entire cell membrane, creating a honeycomb-like pattern. There are few reports in the international literature that describe in detail changes in the immunostaining pattern of syndecan-1 in liver disease compared to normal liver tissue $(37,38)$. Syndecans have mainly heparan sulphate (HS) and some chondroitin sulphate GAG side chains on their extracellular domain, which consist of repeating disaccharide units that are attached to serine residues in the proteoglycan core proteins (11). GAG side chains have a negative charge that allows their interaction with various molecules of ECM with positive charges. The importance of HS has been demonstrated in development and in a variety of physiological and pathological processes of animal cells and tissues $(7,37,42)$. HS may regulate many factors implicated in tissue injury, such as growth factors, cytokines and matrix elements, by affecting their activity, stability and destination (42). Syndecan-1 function is mainly determined by its capacity to bind ligands via HS chains. In addition, HS has been reported to act as co-receptor for the cellular entry of hepatitis B and C viruses $(37,43)$. Interactions between HS and specific ligands are fine-tuned in part by the sulfation pattern of HS. HS may undergo qualitative and quantitative alterations under pathological conditions (37). In the study of Tatrai et al., the HS immunoprofile of rats and human liver and alterations of HS related to liver fibrosis and liver carcinogenesis were investigated. An accumulation and altered localization of HS in CLDs was observed (37). Unlike hepatocytes in the normal liver, where only the sinusoidal area was immunostained, hepatocytes in cirrhotic liver also exhibited HS immunoreaction on the nonsinusoidal lateral cell surfaces. HS staining was intensified overall in tissues with fibrogenic diseases and disaccharide analysis revealed highly sulphated cell surface HS epitopes. In accordance with the localization of HS, in cirrhotic tissue, syndecan-1 localization extended to the entire hepatocyte membrane and sinusoidal staining was intensified (37).

In the present study, increased syndecan-1 expression was statistically correlated with the severity of fibrosis. Although syndecan-1 has been recognized as an essential player in wound healing, its involvement in liver fibrogenesis has not been completely characterized. During liver injury, ECM production exceeds ECM degradation, therefore, ECM becomes insoluble and resistant to protease digestion because of the progressive thickening of fibrotic septa and the increase in chemical cross-linking of collagen $(32,33)$. Underlying this fibrotic response is HSCs activation into 
myofibroblasts and the secretion of cytokines from liver and inflammatory cells, that mediate the activation of several intracellular signalling pathways (2). Studies have highlighted the role of syndecan-1 in lung and cardiac fibrosis and provided new insights into how fibrogenic signals are modulated $(13,17-20)$.

Syndecan-1 overexpression by alveolar epithelium during fibrosis may promote fibroproliferation and may alter alveolar cell phenotype by augmenting TGF $\beta$ and $\mathrm{WNT} / \beta$ catenin fibrogenic signaling pathways (13). In addition, it has been reported that syndecan-1 may regulate the anti-fibrotic microRNA load within extracellular vesicles and therefore, the ability of these vesicles to alter epithelial plasticity and to promote lung fibrosis (13). Syndecan-1 expression has been shown to be up-regulated under pro-inflammatory stimuli in different forms of cardiac disease with fibrosis (19, $21,44,45)$. Interestingly, syndecan-1 expression resulted in cardiac infarct healing and collagen deposition, probably by promoting TGF $\beta$ activation or by activating downstream TGF $\beta$ signaling pathways $(19,44)$.

Syndecan-1 is up-regulated in liver cirrhosis. Increased shedding and serum concentration of the molecule is a characteristic feature of hepatic fibrosis $(28,29,37)$; however, the exact mechanisms underlying its role remain elusive. A recent study showed that syndecan-1 is overexpressed during the earlier stages of fibrogenesis and inhibits fibrosis probably by interfering with TGF $\beta 1$ and by promoting up-regulation of MMP14, a protease playing a critical role in matrix degradation (29). Since syndecan-1 overexpression can reduce expression of TGF $\beta 1$ and its receptor, and HS can negatively regulate the TGF $\beta 1$ response, it was hypothesized that both processes are able to delay fibrogenesis $(29,46,47)$. Syndecan-1 overproduction is also accompanied by increased shedding, a fact that seems to have a benefit in experimental liver fibrosis (29). Both syndecan-1 and TGF $\beta$ concentrations were elevated in the sera of patients with fibrosis and this elevation was parallel to the severity of the disease. Importantly, during the late stages of fibrogenesis, syndecan-1 was down-regulated (31). Syndecan-1 down-regulation can induce activation of HSCs via the TGF $\beta 1 /$ SMAD3 signaling pathway $(25,48)$, and HSCs can be trans-differentiated into myofibrolasts, which produce a large variety of proteins forming connective tissue (2).

In our study, no correlation of syndecan- 1 expression with patient age and sex nor with the etiology of liver fibrosis was demonstrated. However, syndecan-1 overexpression in hepatitis virus $\mathrm{C}$-infected liver tissue has been described, suggesting syndecan-1 as a major receptor for hepatitis virus C internalization into hepatocytes $(23,24,38)$.

In conclusion, in the present study we demonstrated that syndecan-1 overexpression in CLDs is correlated with advanced fibrosis. Because syndecans appear to be involved in the regulation of fundamental pathways in tissue injury, repair and fibrosis, the ongoing investigation of their role in the injured liver tissue may provide new insights into the mechanistic basis of liver disease. Understanding the basic mechanisms of fibrogenesis may improve diagnostic and therapeutic options. Moreover, the characterization of different pathways that are associated with different etiological factors of CLDs may contribute to the development of specific therapies for individual diseases.

\section{Conflicts of Interest}

All the Authors declare that there are no conflicts of interest regarding this study.

\section{Authors' Contributions}

AC: Study design, immunohistochemical interpretation, data analysis, article writing. PK: Study design, review and editing the article. EK: Technical assistance and supervision AK: Technical supervision, data analysis. GG: Supply of liver tissue specimens. NJA: Review and editing the article. ACG: Study design, immunohistochemical interpretation, study supervision, original draft writing. All Authors read, edited and approved the final version of the article.

\section{References}

1 Iredale JP: Models of liver fibrosis: exploring the dynamic nature of inflammation and repair in a solid organ. Clin Invest 117: 539-548, 2007. PMID: 17332881. DOI: $10.1172 / J C I 30542$

2 Hernandez-Gea V and Friedman S: Pathogenesis of liver fibrosis. Annu Rev Pathol 6: 425-456, 2011. PMID: 21073339. DOI: 10.1146/annurev-pathol-011110-130246

3 Elpek GO: Cellular and molecular mechanisms in the pathogenesis of liver fibrosis: An update. World J Gastroenterol 20(23): 72607276, 2014. PMID: 24966597. DOI: 10.3748/wjg.v20.i23.7260

4 Weiskirchen R and Tacke F: Liver fibrosis: Which mechanisms matter? Clin Liver Dis 8(4): 94-99, 2016. PMID: 31041072. DOI: $10.1002 /$ cld. 581

$5 \mathrm{Gu} \mathrm{J}$ and Friedman SL: Hepatic fibrogenesis. Semin Liver Dis 27(4): 413-426, 2007. PMID: 17979077. DOI: 10.1055/s-2007991517

6 Das SK and Vasudevan DM: Genesis of hepatic fibrosis and its biochemical markers. Scand J Clin Lab Invest 68(4): 260-269, 2008. PMID: 18609066. DOI: 10.1080/00365510701668516

7 Xian X, Gopal S and Couchman JR: Syndecans as receptors and organizers of the extracellular matrix. Cell Tissue Res 339(1): 3134, 2010. PMID: 19597846. DOI: 10.1007/s00441-009-0829-3

8 Bernfield M, Götte M, Park PW, Reizes O, Fitzgerald ML, Lincecum $\mathrm{J}$ and Zako M: Functions of cell surface heparan sulfate proteoglycans. Annu Rev Biochem 68: 729-777, 1999. PMID: 10872465. DOI: 10.1146/annurev.biochem.68.1.729

9 Couchman JR: Transmembrane signaling proteoglycans. Annu Rev Cell Dev Biol 26: 89-114, 2010. PMID: 20565253. DOI: 10.1146/annurev-cellbio-100109-104126

10 Iozzo RV and Schaefer L: Proteoglycan form and function: A comprehensive nomenclature of proteoglycans. Matrix Biol 42: 1155, 2015. PMID: 25701227. DOI: 10.1016/j.matbio.2015.02.003 
11 Gondelaud F and Ricard-Blum S: Structures and interactions of syndecans. FEBS J 286(15): 2994-3007, 2019. PMID: 30932318. DOI: 10.1111/febs.14828

12 Stepp MA, Pal-Ghosh S, Tadvalkar G and Pajoohesh-Ganji A: Syndecan-1 and its expanding list of contacts. Adv Wound Care 4(4): 235-249, 2015. PMID: 25945286. DOI: 10.1089/wound. 2014.0555

13 Parimon T, Yao C, Habiel DM, Parimon T, Yao C, Habiel DM, Ge L, Bora SA, Brauer R, Evans CM, Xie T, Alonso-Valenteen F, Medina-Kauwe LK, Jiang D, Noble PW, Hogaboam CM, Deng N, Burgy O, Antes TJ, Königshoff M, Stripp BR, Gharib SA and Chen P: Syndecan-1 promotes lung fibrosis by regulating epithelial reprogramming through extracellular vesicles. JCI Insight 5(17): e129359, 2019. PMID: 31393853. DOI: 10.1172/jci.insight.129359

14 Gopal S: Syndecans in inflammation at a glance. Front Immunol 11: 227, 2020. PMID: 32133006. DOI: 10.3389/fimmu. 2020.00227

15 Teng YH-F, Aquino RS and Park PW: Molecular functions of syndecan-1 in disease. Matrix Biol 31(1): 3-16, 2012. PMID: 22033227. DOI: 10.1016/j.matbio.2011.10.001

16 Manon-Jensen T, Itoh Y and Couchman JR: Proteoglycans in health and disease: the multiple roles of syndecan shedding. FEBS J 277(19): 3876-3889, 2010. PMID: 20840585. DOI: 10.1111/j.1742-4658.2010.07798.x

17 Kliment CR, Englert JM, Gochuico BR, Yu G, Kaminski N, Rosas I and Oury TD: Oxidative stress alters syndecan-1 distribution in lungs with pulmonary fibrosis. J Biol Chem 284(6): 3537-3545, 2009. PMID: 19073610. DOI: 10.1074/jbc.M807001200

18 Frangogiannis NG: Syndecan-1: A critical mediator in cardiac fibrosis. Hypertension 55(2): 233, 2010. PMID: 20048190. DOI: 10.1161/HYPERTENSIONAHA.109.147256

19 Lunde IG, Herum KM, Carlson CC and Christensen G: Syndecans in heart fibrosis. Cell Tissue Res 365(3): 539-552, 2016. PMID: 27411689. DOI: 10.1007/s00441-016-2454-2.

20 Miftode R-S, Şerban I-L, Timpau A-S, Miftode IL, Ion A, Buburuz AM, Costache AD and Costache II: Syndecan-1: A review on its role in heart failure and chronic liver disease patients' assessment. Cardiol Res Pract 2019: 4750580, 2019. PMID: 31815014. DOI: 10.1155/2019/4750580

21 Vanhoutte D, Schellings MW, Götte M, Swinnen M, Herias V, Wild MK, Vestweber D, Chorianopoulos E, Cortés V, Rigotti A, Stepp MA, Van de Werf F, Carmeliet P, Pinto YM and Heymans $\mathrm{S}$ : Increased expression of syndecan-1 protects against cardiac dilatation and dysfunction after myocardial infarction. Circulation 115: 475-482, 2007. PMID: 17242279. DOI: 10.1161/CIRCULATIONAHA. 106.644609

22 Foley EM and Esko JD: Hepatic heparan sulfate proteoglycans and endocytic clearance of triglyceride-rich lipoproteins. Prog Mol Biol Transl Sci 93: 213-233, 2010. PMID: 20807647. DOI: 10.1016/S1877-1173(10)93010-X

23 Shi Q, Jiang J and Luo G: Syndecan-1 serves as the major receptor for attachment of hepatitis $\mathrm{C}$ virus to the surfaces of hepatocytes. J Virol 87(12): 6866-6875, 2013. PMID: 23576506. DOI: $10.1128 /$ JVI.03475-12

24 Grigorov B, Emma Reungoat E, dit Maurin AG, Varbanov M, Blaising J, Michelet M, Manuel R, Parent R, Bartosch B, Zoulim F, Ruggiero F and Pécheur E-I: Hepatitis C virus infection propagates through interactions between syndecan-1 and CD81 and impacts the hepatocyte glycocalyx. Cell Microbiol 19: e12711, 2017. PMID: 27930836. DOI: 10.1111/cmi.12711
25 Nam EJ, Hayashida K, Aquino RS, Couchman JR, Kozar RA, Liu J, and Park PW: Syndecan-1 limits the progression of liver injury and promotes liver repair in acetaminophen-induced liver injury in mice. Hepatology 66(5): 1601-1615, 2017. PMID: 28543100. DOI: 10.1002/hep.29265

26 Baghy K, Tátrai P, Regós E and Kovalszky I: Proteoglycans in liver cancer. World J Gastroenterol 22(1): 379-393, 2016. PMID: 26755884. DOI: 10.3748/wjg.v22.i1.379

27 Yilmaz Y, Eren F, Colak Y, Senates E, Celikel CA and Imeryuz $\mathrm{N}$ : Hepatic expression and serum levels of syndecan 1 (CD138) in patients with nonalcoholic fatty liver disease. Scand $\mathrm{J}$ Gastroenterol 47(12): 1488-1493, 2012. PMID: 23137022. DOI: 10.3109/00365521.2012.725093

28 Zvibel I, Halfon P, Fishman S, Penaranda G, Leshno M, Or AB, Halpern Z and Oren R: Syndecan 1 (CD138) serum levels: A novel biomarker in predicting liver fibrosis stage in patients with hepatitis C. Liver Int 29(2): 208-212, 2009. PMID: 18694404. DOI: $10.1111 / \mathrm{j} .1478-3231.2008 .01830 . x$

29 Regos E, Abdelfattah HH, Reszegi A, Szilak L, Werling K, Szabo G, Kiss A, Schaff Z, Kovalszky I and Baghy K: Syndecan-1 inhibits early stages of liver fibrogenesis by interfering with TGFbeta1 action and upregulating MMP14. Matrix Biol 68-69: 474-489, 2018. PMID: 29454902. DOI: 10.1016/j.matbio.2018.02.008

30 Ishak K, Baptista A, Bianchi L, Callea F, De Groote J, Gudat F, Denk H, Desmet V, Korb G, MacSween RNM, Phillips MJ, Portmann BG, Poulsenm H, Scheuer PJ, Schmid M and Thaler $\mathrm{H}$ : Histological grading and staging of chronic hepatitis. J Hepatol 22(6): 696-699, 1995. PMID: 7560864. DOI: 10.1016/0168-8278(95)80226-6

31 Kleiner DE, Brunt EM, Van Natta M, Behling C, Contos MJ, Cummings OW, Ferrell LD, Liu YC, Torbenson MS, UnalpArida A, Yeh M, McCullough AJ and Sanyal AJ: Design and validation of a histological scoring system for nonalcoholic fatty liver disease. Hepatology 41(6): 1313-1321, 2005. PMID: 15915461. DOI: $10.1002 /$ hep. 20701

32 Issa R, Zhou X, Constandinou CM, Fallowfield J, Millward-Sadler H, Gaca MDA, Sands E, Suliman I, Trim N, Knorr A, Arthur MJP, Benyon RC and Iredale JP: Spontaneous recovery from micronodular cirrhosis: evidence for incomplete resolution associated with matrix cross-linking. Gastroenterology 126(7): 17951808, 2004. PMID: 15188175. DOI: 10.1053/j.gastro.2004.03.009

33 Henderson NC and Iredale JP: Liver fibrosis: cellular mechanisms of progression and resolution. Clin Sci 112(5): 265280, 2007. PMID: 17261089. DOI: 10.1042/CS20060242

34 Ramachandran P and Iredale JP: Reversibility of liver fibrosis. Ann Hepatol 8(4): 283-291, 2009. PMID: 20009126.

35 Charchanti A: Papoudou-Bai A: Samantas E, Papakostas P, Skarlos P, Kanavaros P, Ntritsos G, Agnantis NJ and Goussia AC: Association of low syndecan-1 expression with adverse histopathological parameters in gastric carcinomas. J BUON 24(3): 1106-1112, 2019. PMID: 31424668.

36 Roskams T, Moshage H, De Vos R, Guido D, Yap P and Desmet V: Heparan sulfate proteoglycan expression in normal human liver. Hepatology 21(4): 950-958, 1995. PMID: 7705805.

37 Tátrai P, Egedi K, Somorácz A, van Kuppevelt TH, Dam GT, Lyon M, Deakin JA, Kiss A, Schaff Z and Kovalszky I: Quantitative and qualitative alterations of heparan sulfate in fibrogenic liver diseases and hepatocellular cancer. J Histochem Cytochem 58(5): 429-441, 2010. PMID: 20124094. DOI: 10.1369/jhc.2010.955161 
38 Regős E, Karászi K, Reszegi A, Kiss A, Schaff Z, Baghy K and Kovalszky I: Syndecan-1 in liver diseases. Pathol Oncol Res 26(2): 813-819, 2020. PMID: 30826971. DOI: 10.1007/s12253019-00617-0

39 Stanford KI, Bishop JR, Foley EM, Gonzales JC, Niesman IR, Witztum JL and Esko JD: Syndecan-1 is the primary heparan sulfate proteoglycan mediating hepatic clearance of triglyceriderich lipoproteins in mice. J Clin Invest 119(11): 3236-3245, 2009. PMID: 19805913. DOI: $10.1172 / J C I 38251$

40 Gissen P and Arias IM: Structural and functional hepatocyte polarity and liver disease. J Hepatol 63(4): 1023-1037, 2015. PMID: 26116792. DOI: 10.1016/j.jhep.2015.06.015

41 Afratis NA, Nikitovic D, Multhaupt HAB, Theocharis AD, Couchman JR and Karamanos NK: Syndecans - key regulators of cell signaling and biological functions. FEBS J 284(1): 2741, 2017. PMID: 27790852. DOI: 10.1111/febs.13940

42 Harmer NJ: Insights into the role of heparan sulphate in fibroblast growth factor signalling. Biochem Soc Trans 34(Pt 3): 442-445, 2006. PMID: 16709182. DOI: 10.1042/BST0340442

43 Barth H, Schafer C, Adah MI, Zhang F, Linhardt RJ, Toyoda H, Kinoshita-Toyoda A, Toida T, Van Kuppevelt TH, Depla E, Von Weizsacker F, Blum HE and Baumert TF: Cellular binding of hepatitis $\mathrm{C}$ virus envelope glycoprotein E2 requires cell surface heparan sulfate. J Biol Chem 278(42): 41003-41012, 2003. PMID: 12867431. DOI: 10.1074/jbc.M302267200

44 Bujak M and Frangogiannis NG: The role of TGF- $\beta$ signaling in myocardial infarction and cardiac remodeling. Cardiovasc Res 74(2): 184-195, 2007. PMID: 17109837. DOI: 10.1016/j.cardiores. 2006.10 .002
45 Schellings MWM, Vanhoutte D, C van Almen G, Swinnen M, Leenders JJG, Kubben N, van Leeuwen REW, Hofstra L, Heymans $\mathrm{S}$ and Pinto YM: Syndecan-1 amplifies angiotensin II-induced cardiac fibrosis. Hypertension 55(2): 249-256, 2010. PMID: 20048198. DOI: 10.1161/HYPERTENSIONAHA.109.137885

46 Chen C-L, Huang SS and Huang JS: Cellular heparan sulfate negatively modulates transforming growth factor-beta1 (TGF-beta1) responsiveness in epithelial cells. J Biol Chem 281(17): 1150611514, 2006. PMID: 16492675. DOI: 10.1074/jbc.M512821200

47 Szatmári T, Mundt F, Heidari-Hamedani G, Zong F, Ferolla E, Alexeyenko A, Hjerpe A and Dobra K: Novel genes and pathways modulated by syndecan-1: implications for the proliferation and cell-cycle regulation of malignant mesothelioma. Cells PLoS One 7(10): e48091, 2012. PMID: 23144729. DOI: 10.1371/journal.pone. 0048091

48 Deng M, Xu L, Xie X, Sheng X, Zou Z and Yao M: Downregulation of syndecan-1 expression induces activation of hepatic stellate cells via the TGF- $\beta 1 /$ SMAD3 signaling pathway. Mol Med Rep 20(1): 368-374, 2019. PMID: 31115505. DOI: $10.3892 / \mathrm{mmr} .2019 .10221$ 